\title{
Functional growth inhibition of influenza $A$ and $B$ viruses by liquid and powder components of leaves from the subtropical plant Melia azedarach L.
}

\author{
Kuniaki Nerome ${ }^{1} \cdot$ Kazufumi Shimizu $^{2} \cdot$ Shiori Zukeran $^{1} \cdot$ Yasuhiro Igarashi $^{3} \cdot$ Kazumichi Kuroda $^{2} \cdot$ Shigeo Sugita $^{4}$. \\ Toshikatsu Shibata $^{5} \cdot{\text { Yasuhiko } \text { Ito }^{6} \cdot \text { Reiko Nerome }^{1}}^{1}$
}

Received: 25 January 2018 / Accepted: 21 February 2018 / Published online: 9 April 2018

(c) The Author(s) 2018

\begin{abstract}
We evaluated the anti-influenza-virus effects of Melia components and discuss the utility of these components. The effects of leaf components of Melia azedarach L. on viruses were examined, and plaque inhibition tests were performed. The in vivo efficacy of M. azedarach L. was tested in a mouse model. Leaf components of Melia azedarach L. markedly inhibited the growth of various influenza viruses. In an initial screening, multiplication and haemagglutination (HA) activities of H1N1, H3N2, H5, and B influenza viruses were inactivated by the liquid extract of leaves of M. azedarach L. (MLE). Furthermore, plaque inhibition titres of H1N1, H3N2, and B influenza viruses treated with MLE ranged from $10^{3.7}$ to $10^{4.2}$. MLE possessed high plaque-inhibitory activity against pandemic avian $\mathrm{H} 5 \mathrm{~N} 1, \mathrm{H} 7 \mathrm{~N} 9$, and $\mathrm{H} 9 \mathrm{~N} 2$ vaccine candidate strains, with a plaque inhibition titre of more than $10^{4.2}$. Notably, the buoyant density decreased from 1.175 to $1.137 \mathrm{~g} / \mathrm{cm}^{3}$, and spikeless particles appeared. We identified four anti-influenza virus substances: pheophorbide $b$, pheophorbide a, pyropheophorbide a, and pheophytin a. Photomorphogenesis inside the envelope may lead to removal of HA and neuraminidase spikes from viruses. Thus, MLE could efficiently remove floating influenza virus in the air space without toxicity. Consistent with this finding, intranasal administration of MLE in mice significantly decreased the occurrence of pneumonia. Additionally, leaf powder of Melia (MLP) inactivated influenza viruses and viruses in the intestines of chickens. MLE and MLP may have applications as novel, safe biological disinfectants for use in humans and poultry.
\end{abstract}

Handling Editor: Hans Dieter Klenk.

Kuniaki Nerome

rnerome_ibr@train.ocn.ne.jp

1 The Institute of Biological Resources, 893-2, Nakayama, Nago-shi, Okinawa 905-0004, Japan

2 Division of Microbiology, Nihon University School of Medicine, 30-1, Oyaguchi-kamicho, Itabashi-ku, Tokyo 173-8610, Japan

3 Biotechnology Research Center and Department of Biotechnology, Faculty of Engineering, Toyama Prefectural University, 5180 Kurokawa, Imizu-shi, Toyama 939-0398, Japan

4 Equine Research Institute, Japan Racing Association, 1400-4, Shiba, Shimotsuke-shi, Tochigi 329-0412, Japan

5 Division of Gastroenterology and Hepatology, Nihon University School of Medicine, 30-1, Oyaguchi-kamicho, Itabashi-ku, Tokyo 173-8610, Japan

6 Department of Biomedical Sciences (Graduate School), College of Life and Health Sciences, Chubu University, 1200, Matsumoto-cho, Kasugai, Aichi 487-6501, Japan

\section{Introduction}

As an important respiratory disease, influenza may have the greatest impact of all known highly communicable diseases worldwide. However, in contrast to bacterial diseases, for which various antibiotics have been developed over many decades, the most effective approach for the treatment of viral communicable diseases is establishment of vaccine strategies rather than antiviral drugs. Indeed, to prevent virus infection and related complications caused by epidemic influenza viruses, e.g. H1N1, H3N2, and B influenza viruses, trivalent vaccines have been established to combat $\mathrm{A}$ (H1N1) pdm 09, H3N2 subtype, and B viruses [1]. Despite major vaccination efforts, antigenic variation occurring in epidemic seasons frequently reduces the efficacy of seasonal inactivated or live vaccines in Japan and the United States of America (USA) [2, $3]$. For example, although $100 \%$ of children in primary and junior high schools in the southwestern region of Japan are vaccinated, large outbreaks have occurred in these schools, indicating that influenza virus variants quite different from the 
vaccine strains are prevalent in this area during the spring season [2]. Moreover, in the USA, reduced vaccine efficacy was confirmed during the 2015-2016 season due to the antigenic gap between the $\mathrm{A}(\mathrm{H} 1 \mathrm{~N} 1)$ pdm vaccine strain and epidemic viruses. Importantly, the major reason for the lack of efficacy during the 2016-2017 season was that the vaccine strains were not altered from those in the 2015-2016 season [3].

After the appearance of the H7N9 virus in southern China and subsequent detection in humans, rapid vaccine development was required [4-8]. Accordingly, several vaccines have been developed, such as virus-like particle (VLP) vaccines [9] and DNA-based vaccines [10]. However, despite the use of novel vaccine strategies in humans and poultry, frequent antigenic drift or shift occurs, allowing viruses to evade the effects of vaccines. Thus, it is necessary to design new strategies to overcome the limitations of currently available vaccines. For example, recently developed neuraminidase inhibitors have played an important role in alleviating the symptoms of influenza infection; however, preventive efficacy has not yet been achieved [11]. Based on this information, novel and highly effective anti-influenza drugs are urgently needed.

As an alternative preventative strategy, researchers may consider the use of novel compounds. For example, some chemical and physicochemical compounds targeting H5N1 influenza have been reported [12, 13]. Povidone-iodine-based compounds have been shown to have antiviral and therapeutic activities when administered via intravenous inoculation [14]. Additionally, disodium cromoglycate may also inactivate influenza viruses in the lungs [15]. Effective, safe disinfectants that are mildly disruptive to influenza should be used to improve quality of life. Zhao et al. [16] reported useful antiviral compounds derived from the Melia tree. Melia compounds inhibit herpes simplex virus, flaviviruses, and Mycobacterium tuberculosis [17-20]. Additionally, Melia-derived natural resources extracted with $\mathrm{CO}_{2}$, ethanol, or water have been widely used in folk medicine [21].

In our studies, we also found antiviral substances in subtropical plants, including Melia azedarach L., which is distributed in the Okinawan area of Japan. Our research showed that Melia extracts exhibit a variety of anti-influenza activities. Here, we evaluated the anti-influenza-virus effects of Melia components and discuss the utility of these components.

\section{Materials and methods}

\section{Preparation of leaf powder and its liquid extract from $M$. azedarach $L$.}

Leaves of M. azedarach L. were provided by the forestry department of Nago City, Okinawa, Japan, dried at $65{ }^{\circ} \mathrm{C}$ overnight, and powdered in a machine used to pulverise grain
(MKCA6-25; Masuko Co. Ltd., Saitama, Japan). To prepare the liquid extract (MLE), samples were suspended in nine volumes of distilled water, heated at $115^{\circ} \mathrm{C}$ for $35 \mathrm{~min}$, and centrifuged at 2,900 xg for $30 \mathrm{~min}$ in a Kubota 7780 centrifuge (Kubota, Tokyo, Japan) fitted with a Kubota AG-1K rotor. The resulting supernatant was mixed with an equal volume of ethanol (Wako, Tokyo, Japan), incubated overnight at $4{ }^{\circ} \mathrm{C}$, and centrifuged at 2,900 xg for $20 \mathrm{~min}$. Ethanol was then removed by evaporation, and the dried material was resuspended in an equal volume of distilled water and filtered through a 10-kDa membrane (Pellicon 2 Mini Filters; Millipore Corporation, Germany). The resuspended sample was adjusted to contain $10.5 \mathrm{mg}$ Melia extract $/ \mathrm{mL}$ and was thereafter considered to have an activity of $1 \mathrm{U}$ in subsequent examinations. To obtain leaf powder (MLP), dried leaves from the Melia tree were powdered as described above and dried at $37^{\circ} \mathrm{C}$ for a few days.

\section{Cells and viruses}

Madin-Darby canine kidney (MDCK) cells were grown in minimum essential medium containing $5-10 \%$ foetal calf serum. A/PR/8/34 (H1N1) (PR-8), A/Okinawa/248/2009 (H1N1) pdm (Okinawa), A/Moscow/1/00 (H3N2) (Moscow), B/Yamagata/16/88 (Yamagata), and A/duck/Singapore-Q/F119-3/97 (H5N3) (Singapore) strains of influenza virus were propagated in MDCK cells or 10-day-old embryonated chicken eggs. Except for the Okinawa strain, all of the above strains were obtained from the Non-Profit Organization of Biomedical Science Association (Tokyo, Japan); the Okinawa strain was kindly provided by the Okinawa Prefectural Institute of Health and Environment. In addition, the following low pathogenic avian influenza (vaccine seed) viruses were used, which were kindly provided by and imported (Import Permit No.: 29 douken 322, issued on 12 June, 2017 by Ministry of Agriculture, Forestry and Fisheries, Japan) from Dr. R. G. Webster, St. Jude Children Research Hospital, Memphis, TN, USA: RG-A/Barn Swallow/Hong Kong/1161/2010-A/PR/8/34 H5N1 [R] (6+2): (Swallow HK H5), RG-A/Anhui/2013-A/PR/8/34 H7N9 [R] (6+2): (Anhui H7), and A/Hong Kong/308/2014 -A/PR/8/34 H9N2 [R] (6+2): (HK H9).

\section{Plaque assay}

The infectivity of the challenge influenza viruses was adjusted to $200 \mathrm{PFU} / \mathrm{mL}$, and $100 \mu \mathrm{L}$ of each virus was mixed with an equal volume of MLE. Mixtures were incubated at $35{ }^{\circ} \mathrm{C}$ for $30 \mathrm{~min}$ and spread on $30-\mathrm{mm}$ culture plates containing monolayers of MDCK cells. Subsequently, cells were overlaid with $3 \mathrm{~mL}$ of $1 \%$ agar containing $15 \mu \mathrm{g} /$ $\mathrm{mL}$ acetylated trypsin from bovine pancreas (Sigma-Aldrich, Germany). After 3 days at $35{ }^{\circ} \mathrm{C}$ in a $5 \% \mathrm{CO}_{2}$ incubator, the agar of the overlaid media was removed, and cells were fixed 
at room temperature for $1 \mathrm{~h}$ with $1 \mathrm{~mL}$ of $3.7 \%$ formaldehyde in phosphate-buffered saline (PBS), rinsed with water, and stained with $1 \mathrm{~mL}$ of methylene blue tetrahydrate (Wako) in distilled water. Finally, plates were rinsed with water and dried at room temperature, and plaques were counted.

\section{Growth inhibition and HA inactivation tests}

Growth inhibition was examined on the basis of the cytopathic effect (CPE). A $0.1-\mathrm{mL}$ aliquot of 10 -fold-diluted challenge viruses was mixed with $0.9 \mathrm{~mL}$ of MLE sample, and the mixtures were incubated at $37{ }^{\circ} \mathrm{C}$ for $60 \mathrm{~min}$. The mixtures were then inoculated onto monolayers of MDCK cells, which were incubated at $37^{\circ} \mathrm{C}$ for $30 \mathrm{~min}$.

\section{HA test}

Viruses were two-fold serially diluted in $50 \mu \mathrm{L}$ of PBS in 96-well U-bottom plates, and $50 \mu \mathrm{L}$ of $0.5 \%$ (v/v) chicken erythrocytes in PBS was added and mixed. After $30 \mathrm{~min}$ of incubation, HA titres were determined based on the last dilution showing complete hemagglutination, as described previously [13].

\section{Physicochemical and morphological characterisation of viruses treated with Melia extract}

A/PR-8 virus was purified by centrifugation at $142,190 \times \mathrm{g}$ for $4 \mathrm{~h}$ along a $10-50 \%(\mathrm{w} / \mathrm{w})$ sucrose density gradient and treated with concentrated Melia extract for $120 \mathrm{~min}$ at $37^{\circ} \mathrm{C}$. Samples were then stained with $2 \%$ phosphotungstic acid and examined by electron microscopy (H500; Hitachi, Japan). For comparison, untreated virus was purified along a $10-50 \%(w / w)$ sucrose density gradient by centrifugation at $142,190 \times \mathrm{g}$ for $4 \mathrm{~h}$ in an SW 50.1 rotor, and buoyant density was determined by centrifugation at $142,190 \times \mathrm{g}$ for $4 \mathrm{~h}$ along the $10-50 \%(w / w)$ sucrose density gradient. Morphological observation of the virus particles was performed using a Hitachi H7000 electron microscope, as described previously [9].

\section{Identification of active components in Melia extract}

Dried Melia leaves $(1 \mathrm{~kg})$ were extracted with $5 \mathrm{~L}$ of distilled water, filtered through a 10-kDa membrane (Pellicon 2 Mini Filter; Millipore Corporation), dried, and further extracted for $1 \mathrm{~h}$ with $1 \mathrm{~L}$ of $1: 1 \mathrm{CHCl}_{3}-\mathrm{MeOH}$ (Wako). For chemical analysis, approximately $200 \mathrm{~L}$ of this preparation was dried and resuspended. The aqueous layer, which exhibited activity, was collected and dried, yielding $1.46 \mathrm{~g}$ of dark solid. The extract was fractionated by silica gel column chromatography $\left(\mathrm{CHCl}_{3} / \mathrm{MeOH}=1: 0,20: 1,10: 1,4: 1,2: 1,1: 1\right.$, or 0:1, $\mathrm{v} / \mathrm{v}$ ), and antiviral activity against PR-8 influenza virus was detected in fractions CM4:1 (730 mg) and CM2:1 (168 mg). CM4:1 $(50 \mathrm{mg}$ ) was fractionated by high-performance liquid chromatography (HPLC) along a gradient of $\mathrm{MeCN}-0.1 \%$ $\mathrm{HCO}_{2} \mathrm{H}$ (74\% MeCN for 0-20 min, 74-100\% for 20-25 min, and $100 \%$ for $25-36 \mathrm{~min})$ to yield components $\mathrm{A}(2.6 \mathrm{mg})$, B (0.5 mg), C (1.0 mg), and D (0.2 mg). Based on nuclear magnetic resonance (AVANCE 500; Bruker Daltonics K.K., Japan), mass spectrometry (MicroTOF Focus; Bruker Daltonics K.K.), and UV spectrometry (U-3210; Hitachi), the components were identified as pheophorbide a, pheophorbide $\mathrm{b}$, pyropheophorbide a, and pheophytin a, respectively.

\section{Safety of Melia extract}

Samples of Melia extract were filtered through ultramembrane filters (Millipore Corporation) with molecular weight cut offs of $10,30,50$, and $100 \mathrm{kDa}$ and sterilised using a $200-\mu \mathrm{m}$ filter. In vitro toxicity was assessed based on cytopathic morphological changes (CPEs) in MDCK cells. In vivo mortality was evaluated in 4-week-old ddY specific pathogen-free $(\mathrm{SPF})$ mice $(\mathrm{n}=5)$ purchased from Japan SLC (Shizuoka, Japan). Mice were orally administered with $0.5 \mathrm{~mL}$ of sample, and mortality was examined daily for 7 days. Mouse and chicken experiments were approved and performed in accordance with the Fundamental Rules for Animal Experiments and the Guidelines for Animal Experiments Performed at The Institute of Biological Resources published by the Animal Welfare and Animal Care Committee including the Animal Ethics Committee of the Institute of Biological Resources, Okinawa, Japan.

\section{Virus clearance from air space}

Samples of PR-8 (H1N1) virus were adjusted to $2 \times 10^{7} \mathrm{PFU} /$ $\mathrm{mL}$, and $5 \mathrm{~mL}$ was sprayed for 10 min into a $96-\mathrm{L}$ closed chamber. Subsequently, a sample of Melia extract was also sprayed into the same chamber for another $10 \mathrm{~min}$. Virus particles were then recovered into the MEM by aspirator and infectivity was measured by the PFU method, as described previously.

\section{Inactivation of virus infectivity by Melia powder (MLP)}

We prepared three stainless steel plates $\left(560 \mathrm{~cm}^{2}\right)$, which were covered $\left(0.015 \mathrm{~g} / \mathrm{cm}^{2}\right)$ with MLP, bamboo powder (Bam), or wood shavings (Wood) and placed into the $96-\mathrm{L}$ closed chamber. Then, $5 \mathrm{~mL}$ of Singapore virus $\left(5 \times 10^{6} \mathrm{PFU} / \mathrm{mL}\right)$ was sprayed onto the plate for $30 \mathrm{~min}$, using a nebulizer kept in the chamber. After infection, we collected the infected powder sample into a tube from the plate. Subsequently, $9 \mathrm{~mL}$ of PBS was added to $1 \mathrm{~g}$ of the 
sample and kept at room temperature for 30 min to extract the reaction fluid. The same procedure was repeated for the remaining two sample plates. Prior to plaque formation tests, the three test specimens were filtered through a $0.2-\mu \mathrm{m}$ membrane filter.

\section{Virus clearance test in the intestines}

Different concentrations of Melia powder were mixed with chicken bait at ratios ranging from 0.1 to $10 \%$, and their effects in chickens were investigated. In this test, 10-folddiluted A/Singapore virus was also orally inoculated, and virus titres were examined in the chicken droppings for the next 2 days.

\section{In vivo antiviral activity}

Female SPF ddY mice (4 weeks of age) were purchased from Japan SLC Co. Ltd. (Shizuoka, Japan). Mice were administered Melia extract or PBS intranasally and infected with PR-8 virus at an infectivity of 10-20 PFU $(n=5$ mice per group) using a $100 \mu \mathrm{L}$ plastic pipette tip. Mice were sacrificed on the indicated days after infection, and pneumonia was scored on a scale of 0-5 after dissection, depending on the number of infected lobes in the lung.

\section{Results}

\section{Growth inhibition of influenza viruses by MLE}

First, we screened subtropical plants collected in the Okinawan area of Japan for anti-influenza activity. Our results showed that MLE inactivated the HA activity of human and avian influenza viruses tested. Moreover, as seen in Table 1, four human and three avian strains of influenza virus showed markedly plaque reduction following treatment with MLE. For example, 50\% plaque inhibition titres of four human influenza virus ranged from $10^{3.7}$ and $10^{4.2}$. We also examined growth inhibition of three avian vaccine candidate strains with the use of 10 -folddiluted MLE samples. It was quite evident that $50 \%$ plaque inhibition titres of avian viruses were $10^{2.6}$ (Anhui H7), $10^{3.6}$ (HK H 9), and $10^{3.7} \mathrm{PFU} / \mathrm{mL}$ (Swallow HK H 5).

\section{Physicochemical and morphological analyses of growth inhibition mechanisms}

Since the HA activities of human and avian viruses were inactivated by MLE treatment, highly purified A/PR- 8 virus was treated with MLE for $120 \mathrm{~min}$, and the mixture was subjected to $10-50 \%(\mathrm{w} / \mathrm{w})$ sucrose density gradient centrifugation at

Table 1 Screening of the anti-influenza virus activity of MLE

\begin{tabular}{|c|c|c|c|}
\hline \multirow[b]{2}{*}{ Test viruses } & & \multicolumn{2}{|l|}{ Sample treatment } \\
\hline & & \multirow{2}{*}{$\begin{array}{l}\text { PBS } \\
\text { HA titre }\end{array}$} & \multirow{2}{*}{$\begin{array}{l}\text { MLE } \\
\text { HA titre }\end{array}$} \\
\hline HA subtypes & Strains & & \\
\hline & 1. Human strains & & \\
\hline H1N1 & $\mathrm{A} / \mathrm{PR} / 8 / 34$ & 256 & $-*$ \\
\hline \multirow[t]{3}{*}{$\mathrm{H} 3 \mathrm{~N} 2$} & A/Moscow/1/00 & 64 & 8 \\
\hline & B/Yamagata/16/88 & 128 & 8 \\
\hline & 2. Avian strain & & \\
\hline H5N3 & A/duck/singapore-Q/F119-3/97 (H5N3) & 128 & $-*$ \\
\hline \multicolumn{4}{|c|}{ Inactivation efficacy against plaque infectivity } \\
\hline \multirow[t]{2}{*}{ HA Subtypes } & Strains & $\begin{array}{l}50 \% \text { plaque } \\
\text { Inhibition titre/ml }\left(\log _{10}\right)\end{array}$ & \\
\hline & 1. Human strains & & \\
\hline H1N1 & $\mathrm{A} / \mathrm{PR} / 8 / 34$ & 4.0 & \\
\hline H1N1 & A/Okinawa/248/2009 & 4.2 & \\
\hline \multirow[t]{3}{*}{$\mathrm{H} 3 \mathrm{~N} 2$} & A/Moscow/1/00 & 3.8 & \\
\hline & B/Yamagata/16/88 & 3.7 & \\
\hline & 2. Avian strains & & \\
\hline $\mathrm{H} 5 \mathrm{~N} 1$ & RG-A/Barn Swallow/HK/1161/2010-A/PR/8/34 & 3.7 & \\
\hline H7N9 & RG-A/Anhui/1/2013-A/PR/8/34 & 2.6 & \\
\hline H9N2 & RG-A/HK/308/2014-A/PR/8/34 & 3.6 & \\
\hline
\end{tabular}

*: HA titre less than 32 
35,000 rpm for $4 \mathrm{~h}$ using a SW 501 swing rotor. Notably, two different virus bands were detected in two centrifugation tubes (Fig. 1(a)). The two target virus samples were correctly analysed under a clear linear sucrose concentration, showing two different peaks (Fig. 1(a)). The first peak was detected in untreated virus specimens (Fig. 1(a)). This was different from that of the MLE-treated virus sample, in which the protein peak was present in lighter fractions 9-10; however, HA activity was not determined in these fractions (Fig. 1(a)). Moreover, the buoyant density of MLE-treated virus was decreased from $1.175 \mathrm{~g} / \mathrm{cm}^{3}$ of normal virions to $1.137 \mathrm{~g} / \mathrm{cm}^{3}$ (Fig. 1(a)). Conversely, protein and HA peaks of normal and MLE-treated viruses were present in fraction 7 (Fig. 1(a)). As shown in Fig. 1(b), typical normal virions of influenza virus were surrounded with dense projections (two pictures on the left). In contrast, all spikes on the surface of MLE-treated virus were completely removed from virus particles (two pictures on the right).

\section{Identification of chemical structures of anti-influenza components from Melia specimens}

Crushed leaves were collected by centrifugation and extracted with a mixture of chloroform and methanol. The lower chloroform layer was concentrated to give a crude extract, which was further fractionated by silica gel column chromatography (Fig. 2(a)). The active fraction was then
Fig. 1 Buoyant density analysis and electron microscopic examination of MLE-treated and untreated influenza viruses. (a) Estimation of the buoyant density of $\mathrm{A} /$ PR-8 (H1N1) influenza virus particles treated with or without MLE. Samples were subjected to $10-50 \%$ sucrose $(\mathrm{w} / \mathrm{w})$ density gradient centrifugation at $142,190 \mathrm{xg}$ for $4 \mathrm{~h}$ and separated into 21 fractions. Examination of the linearity of the sucrose concentration and confirmation of virus bands. Fractionation patterns of MLEtreated virus and fractionation patterns of untreated normal virus. (b) Electron microscopic examination of virus particles treated with and without MLE. Untreated viruses were two pictures on the left and MLEtreated viruses were two on the right

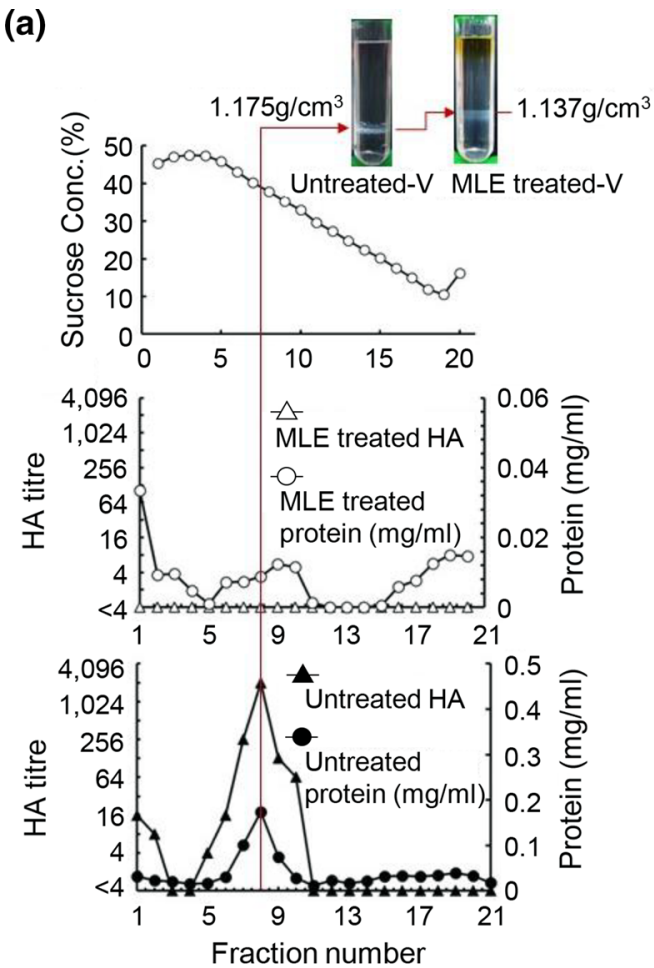

(b)
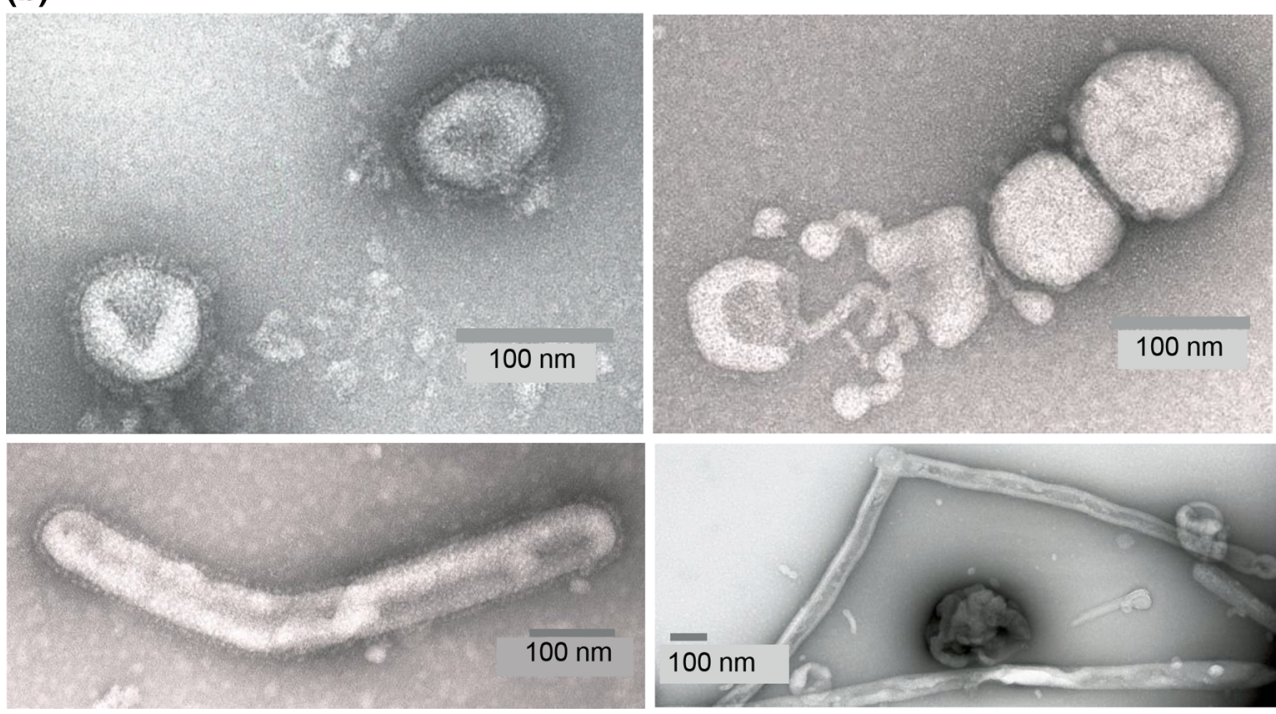
Fig. 2 Chemical analysis of MLE and antiviral activity of purified components. (a) Identification, purification, and structure of MLE components. (b) Antiviral activity of each purified component, alone or in combination, against PR- 8 virus (a)

Dried leaves of Melia azedarach $(111 \mathrm{~g})$ in water $(1 \mathrm{~L})$

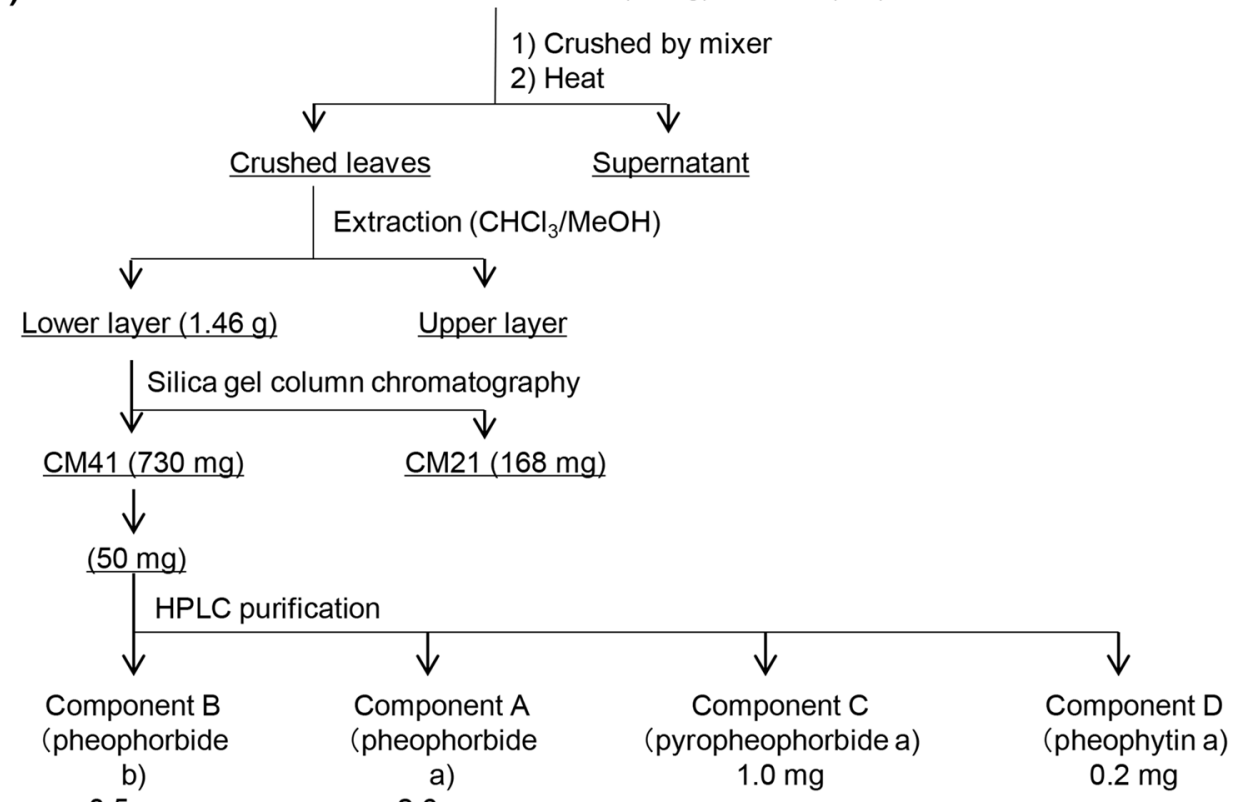

$1.0 \mathrm{mg}$
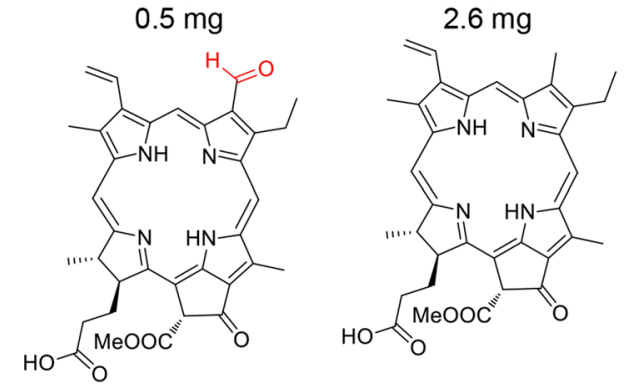

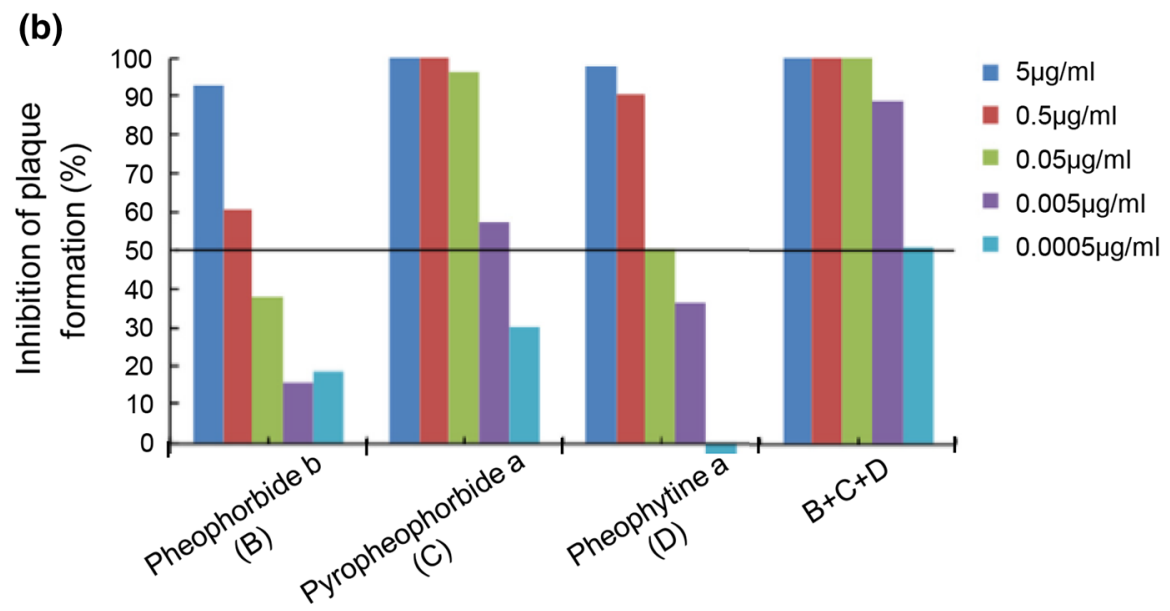

subjected to HPLC fractionation, and the antiviral activity of each fraction was evaluated (Fig. 2(b)). Structure analysis of the most active fraction revealed that the major active component was pheophorbide a, a degraded product of chlorophyll. Three more components, pheophorbide $b$, pyropheophorbide a, and pheophytin, were also identified as active components on the basis of mass spectrometry and UV spectral data (Fig. 2(a)). As a result, the antiviral activity of the mixture of pheophorbide b, pyropheophorbide a, and pheophytin a showed enhanced antiviral activity (Fig. 2(b)). 
(a)

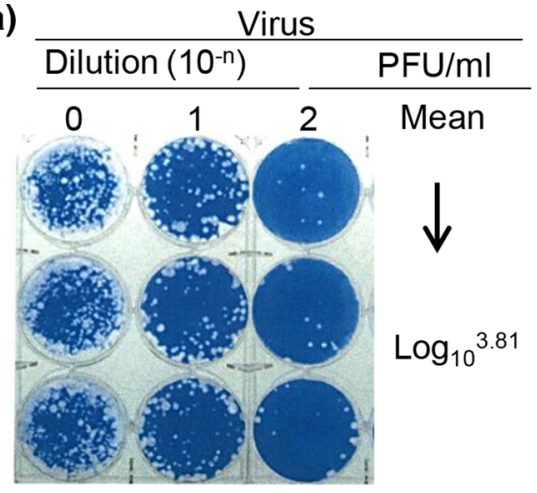

(b)

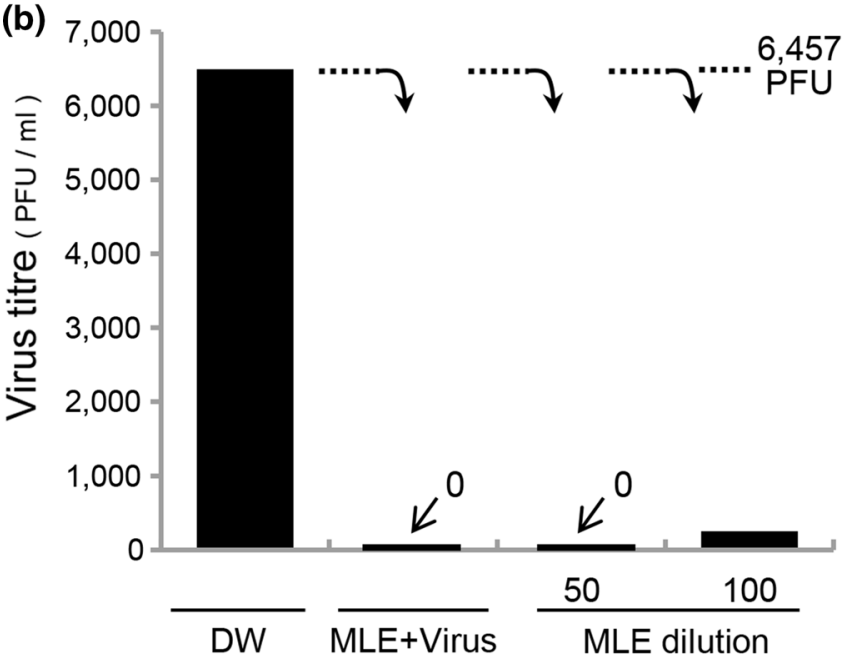

(d)

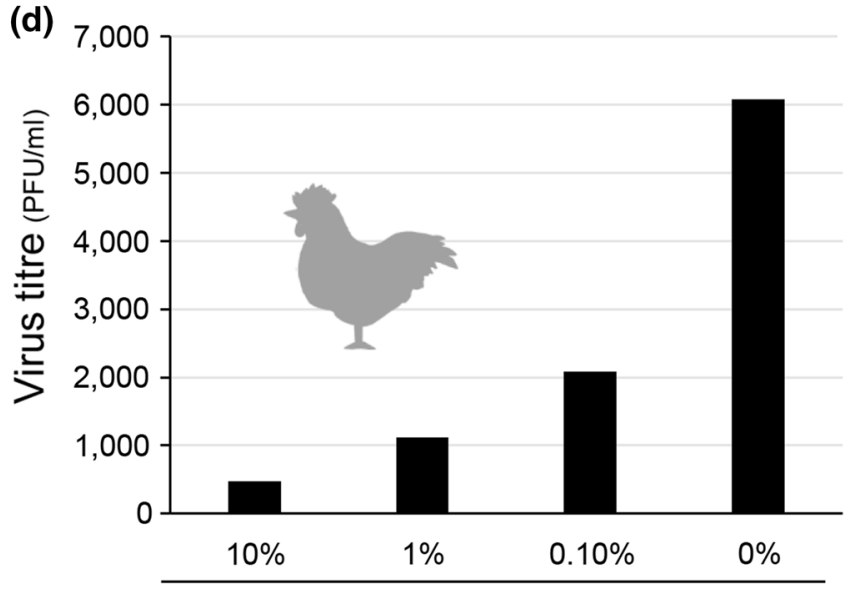

Concentration of MLP in bait

Fig. 3 Spraying and powder treatment efficacy of MLE and MLP against virus inactivation. (a) Plaque titration of the three sprayed samples. Distilled water-sprayed virus (left), 50-fold-diluted MLEsprayed samples (centre) and 100-fold-diluted MLE-sprayed sample (right). (b) Virus inactivation efficacy in the air space with MLE spray. (c) Virus inactivation efficacy of MLE powder (MLP), Bamboo
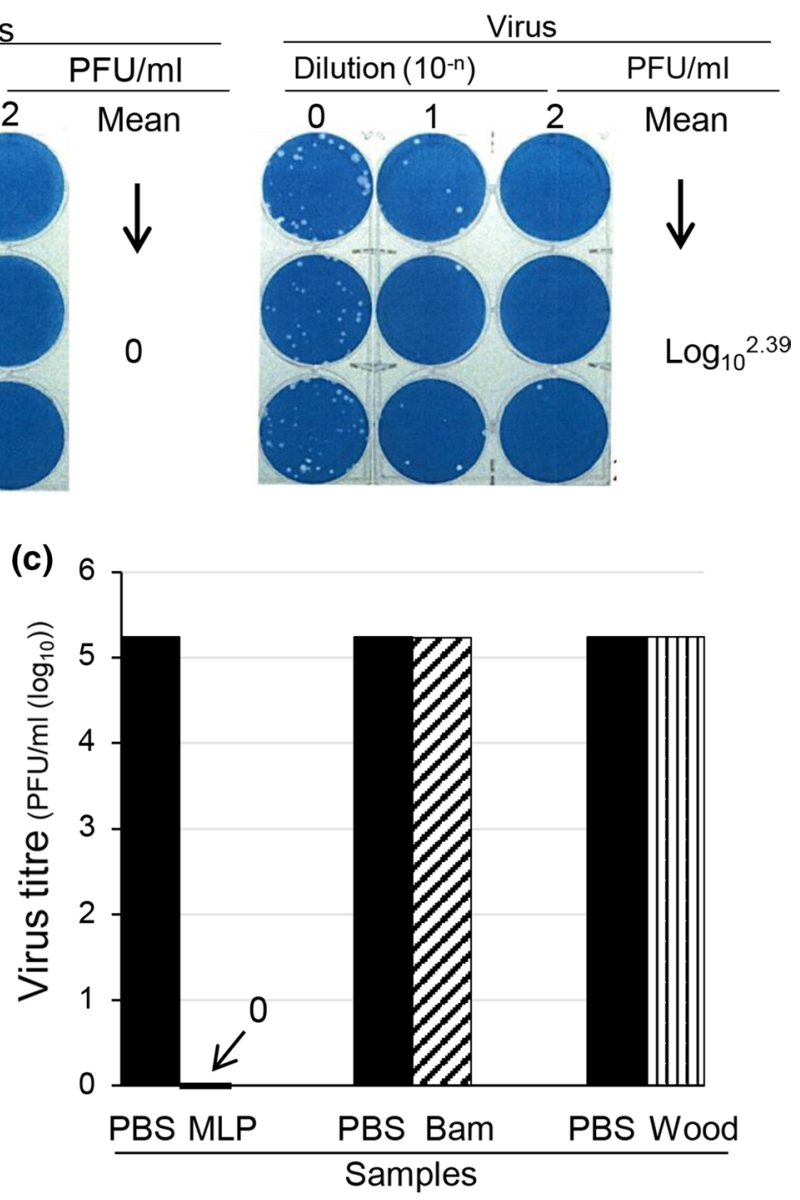

(e)

\section{Biological activity}

\begin{tabular}{|c|c|c|c|}
\hline \multirow{2}{*}{$\begin{array}{c}\text { Molecular weight } \\
\qquad(\mathrm{kDa})\end{array}$} & \multicolumn{2}{|c|}{ Toxicity } & \multirow{2}{*}{$\begin{array}{c}\text { Antiviral } \\
\text { activity }\end{array}$} \\
\hline & $\begin{array}{l}\text { Mouse } \\
\text { mortality }\end{array}$ & $\begin{array}{l}\text { MDCK } \\
\text { cells }\end{array}$ & \\
\hline 100 & - & - & + \\
\hline 50 & - & - & + \\
\hline 10 & - & - & + \\
\hline 5 & - & - & n.t. \\
\hline 3 & - & - & n.t. \\
\hline
\end{tabular}

n.t. : not test

and Wood powder. Challenge viruses possessing $5 \times 10^{6} \mathrm{PFU}$ infectivity were mixed with MLP on the plates and allowed to stand at room temperature. After $30 \mathrm{~min}$ their infectivity were measured. (d) Virus infectivity in the chicken intestine, which ate MLP including bait. (e) Safety test MLE toxicity in MDCK cells and mice 


\section{Virus clearance efficacy of MLE in the closed air space}

Next, we investigated virus clearance or removal efficacy in a closed air space with MLE. In this experiment, viruses $\left(2 \times 10^{7} \mathrm{PFU}\right)$ were sprayed for $10 \mathrm{~min}$ in a revelation chamber in a safety cabinet ( $90 \mathrm{~L}$ air space), and $10 \mathrm{~min}$ later, distilled water (control) or MLE test samples were subsequently sprayed for $10 \mathrm{~min} .10^{3.81} \mathrm{PFU} / \mathrm{mL}$ of test virus was observed in the distilled water control (Fig. 3(a), left). In contrast, the above active viruses were completely inactivated or removed by administration of 50-fold-diluted MLE (Fig. 3(a), center), whereas $10^{2.39} \mathrm{PFU} / \mathrm{mL}$ of virus remained in the air space in samples treated with 100-folddiluted MLE (Fig. 3(a), right). These results were summarized in Fig. 3(b) together with the complete disappearance of MLE + virus sample. The finding shown in Fig. 3(a)(b), indicates Melia samples have the potential for virus clearance in a closed air space.

\section{Efficacy of MLP in influenza virus inactivation}

To evaluate the virus inactivation efficacy of MLP, Singapore virus sprayed onto bamboo powder (Bam), wood savings (Wood), or MLP on the stainless steel plates was used to simulate the ground at poultry farms. The Bam and Wood test specimens showed high titres similar to virus control (PBS) titre of $10^{5.2} \mathrm{PFU} / \mathrm{mL}$ (Fig. 3(c)). In contrast, the MLP test specimen showed complete inactivation (Fig. 3(c)). Furthermore, in a chicken model infected with the low pathogenic Singapore virus, high virus titres of approximately $6,000\left(10^{3.78}\right) \mathrm{PFU} / \mathrm{mL}$ were observed in droppings, and virus titres gradually decreased as the concentration of MLP was increased from $0.1 \%$ to $10 \%$ in the bait (Fig. 3(d)). These experiments demonstrate that MLP markedly reduced virus titres in the intestine of chickens.

\section{Safety analysis of the MLE sample}

To apply MLE in the treatment of human disease, a minimum safety requirement must be met. As shown in Fig. 3(d), partially purified MLE did not show any CPE in MDCK cells or mortality in mice.

\section{Prevention of experimental pneumonia in mice following MLE treatment}

Finally, we examined the efficacy of MLE in the prevention of mouse pneumonia. As shown in Fig. 4(a), body weights of mice treated with PBS decreased from 3 days after infection, whereas mice treated with MLE (Fig. 4(b)) retained their body weight until 5 days after infection. Moreover,
Fig. 4 Preventive efficacy of MLE against influenza-related pneumonia in mice. (a)-(c) Mean body weights in mice pretreated with PBS (a) or MLE (b) or prior to infection, mice treated with MLE containing PR-8 virus (MLE+ virus) (c). (d) Macropathological comparison of pneumonia occurrence in mice treated with or without MLE. Morphological and colour changes in the dorsal and abdominal sides of the lung. (e) Mean pneumonia score in the lungs of three mouse groups treated with MLE, MLE-virus mixture (MLE + V), and PBS. (f) Survival rates in the three mouse groups treated with PBS (control), MLE, and MLE + V samples

mice treated with a virus-MLE mixture showed a constant increase in body weight (Fig. 4(c)). Consistent with these findings, the occurrence of pneumonia in these three mouse groups differed (Fig. 4(d)). For example, four of the mouse lungs obtained from MLE-pretreated mice showed pink shading (Fig. 4(d)). In contrast, most lungs obtained from PBS control mice showed a strong black colour, indicating severe pneumonia (Fig. 4(d)). This conclusive evidence was further evaluated based on the degree of pneumonia in mouse lungs (Fig. 4(e)). Scores for pneumonia occurrence in MLE-treated, MLE+virus-treated, and PBS-treated mice were $1.5,0.5$, and 5 , respectively. Consistent with the above results, MLE-treated mice showed higher preventive efficacy (80\% survival; Fig. 4(f)), which was apparently different from that of PBS-treated mice ( $40 \%$ survival) in the absence of the MLE component (Fig. 4(f)). In contrast, the survival rate in mice treated with the MLE-virus mixture was $100 \%$. These experiments suggest that the MLE and MLP components could prevent or alleviate the damage attributable to influenza virus infection.

\section{Discussion}

In this study, we found that the growth of influenza A and $B$ viruses was markedly influenced by the presence of MLE and/or MLP. Additionally, the effects of MLE and MLP on growth inhibition could overcome the risk of antigenic differences in types and subtypes of all orthomyxovirus family members. Based on these findings, MLE may be used to supplement inactivated or live influenza vaccines, which are greatly influenced by the frequent occurrence of antigenic drift or limited antigenic shift.

Influenza viruses spread from human to human through direct droplets within a short distance of 1-2 m. However, the presence of other important transmission routes should be considered. For example, transmission may occur through coughing and sneezing, during which many virus particles are scattered in the air space and human environment; the transmission of these aerosols may play important roles in the rapid spread of influenza [22]. 


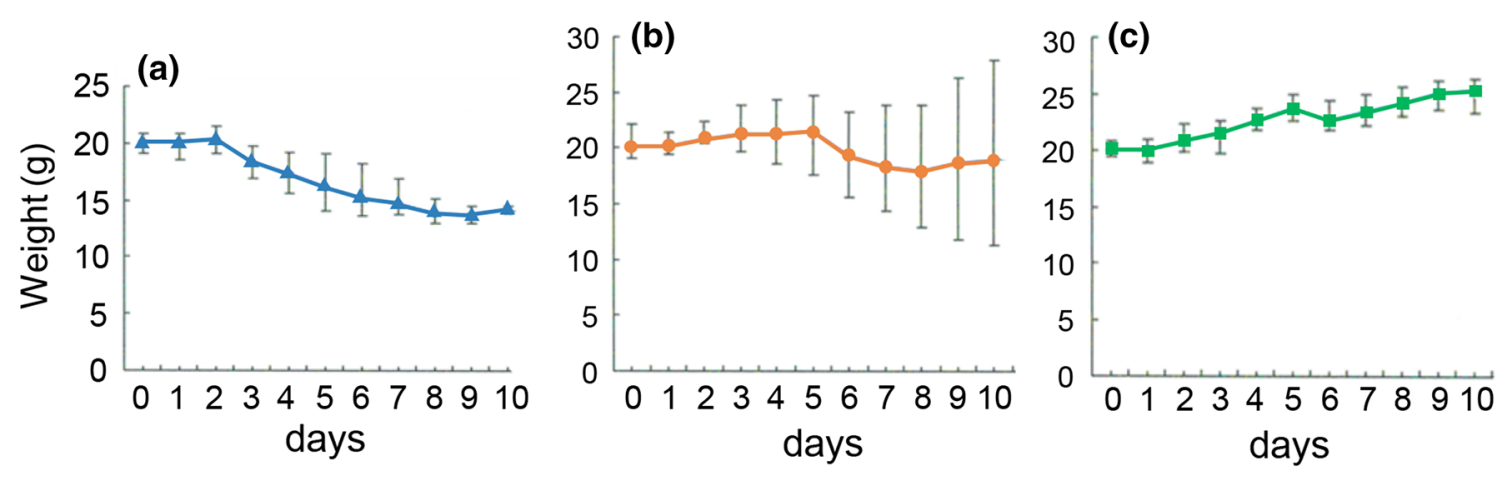

(d)

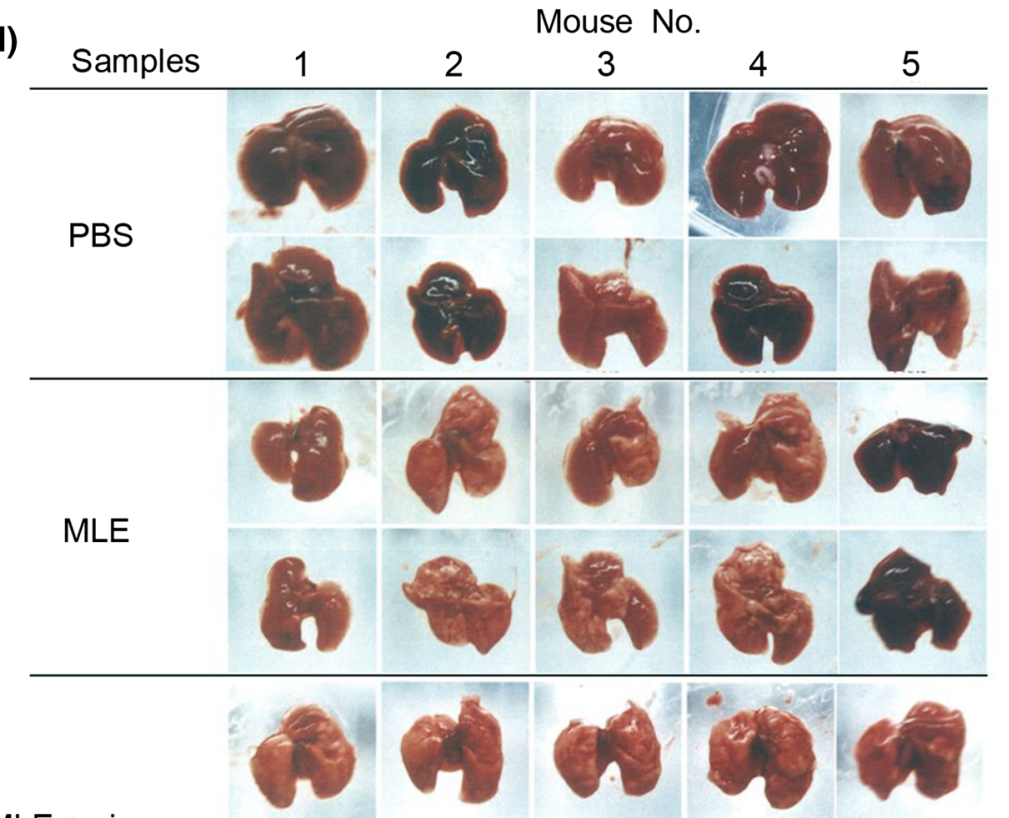

MLE + virus
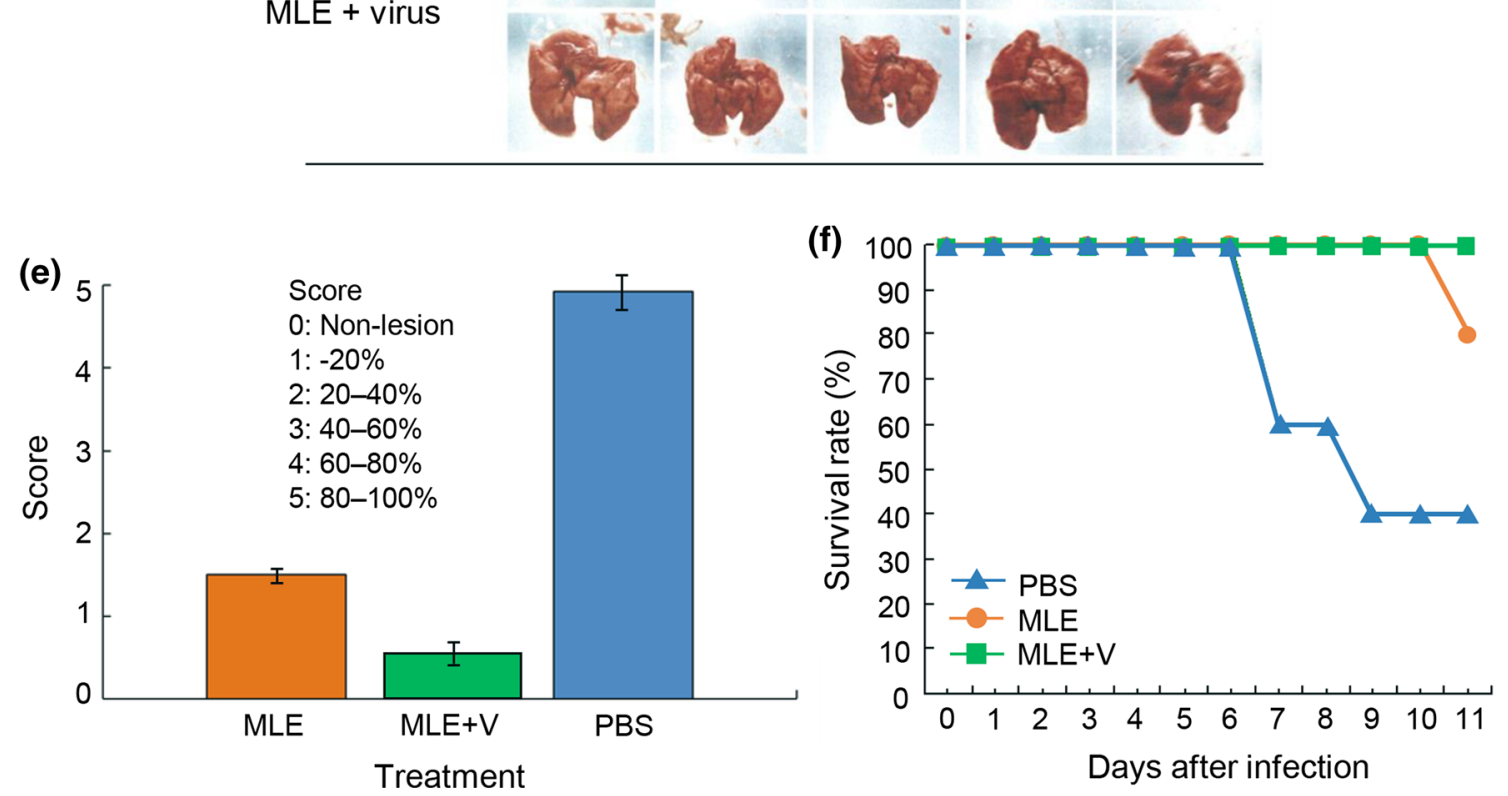
In 1997, a commercial jet airplane experienced engine trouble and was unable to take off for approximately $4 \mathrm{~h}$. A woman infected with influenza virus had boarded the airplane and suffered from a violent acute onset of influenza infection, resulting in frequent coughing [23]. In this case, Moser et al. investigated the infection rate in all passengers and the number of hours they stayed on the airplane in detail. They showed that the infection rate for 5 passengers who stayed for less than 1 hour, 9 passengers who stayed for 1-3 hours, and 29 passengers who stayed for more than 3 hours were $54 \%, 56 \%$, and $86 \%$, respectively [23], suggesting that most passengers were infected through an aerosol route originating from the single patient [23]. Thus, many influenza cases, such as those occurring in families, schools, companies, or the general social population, may be attributable to aerosol infection, although droplet infection is also an important transmission route.

When considering the above complicated transmission of aerosol influenza viruses in the living air space, countermeasures against influenza, including removal or killing of floating viruses outside the body, are essential. As described above, MLE samples could efficiently remove or kill floating viruses in a closed air space, and through this mode of virus inactivation, infection could be prevented in some individuals. Thus, these results may be important for decreasing the spread of the virus through social populations.

Based on our findings, we suggest that MLE may have applications in viral prevention. Indeed, Zhao et al. reviewed a large number of dimonoids isolated from Melia trees and showed that some compounds had antiviral effects on herpes simplex virus-1 and vesicular stomatitis virus [16].

In summary, our findings show that MLE could obviously remove or kill the floating virus in the air space, leading to decreased influenza infection. Moreover, MLP could inactivate or remove influenza viruses distributed on the ground at poultry farms or in the intestines of chickens, suggesting reduced rates of avian influenza virus infection at poultry farms or even in nature. Thus, Melia-derived compounds may be established as strategic countermeasures combinable with influenza vaccines and antiviral drugs. Vaccines and anti-influenza drugs are important measures against viral infection. In contrast, measures for the treatment of influenza virus using biological resources such as Melia may act outside the living body or cells, suggesting another effective strategy for treating humans and animals. Further studies are needed to assess whether such an approach may be efficacious when combined with appropriate vaccines.

Acknowledgements The authors thank Mr. S. Mukai and Ms. S. Matsuda (Institute of Biological Resources, Okinawa) for their skilful technical help and general support.

Funding This work was partially supported by a grant from the Okinawa New Industry Creation Project for fiscal year 2011 and 2012 by the Okinawa Industry Promotion Public Corporation trusted from the Okinawa prefectural government.

\section{Compliance with ethical standards}

Conflict of interest The authors declare that they have no conflict of interest.

Data availability statement All data generated or analysed during this study are included in this published article.

Open Access This article is distributed under the terms of the Creative Commons Attribution 4.0 International License (http://creativecommons.org/licenses/by/4.0/), which permits unrestricted use, distribution, and reproduction in any medium, provided you give appropriate credit to the original author(s) and the source, provide a link to the Creative Commons license, and indicate if changes were made.

\section{References}

1. Wright PF, Newman G, Kawaoka Y (2013) Orthomyxoviruses. Fields Virol 6:1186-1243

2. Kanegae Y, Sugita S, Endo A et al (1990) Evolutionary pattern of the Hemagglutinin gene of influenza B viruses isolated in Japan: cocirculating lineages in the same epidemic season. J Virol 64:2860-2865

3. Jackson ML, Chung JR, Jackson LA et al (2017) Influenza vaccine effectiveness in the united states during the 2015-2016 season. N Engl J Med 377:534-543

4. Arunachalam R (2014) Adaptive evolution of a novel avian-origin influenza A/H7N9 virus. Genomics 104:545-553

5. $\mathrm{Ke} \mathrm{C}, \mathrm{Lu} \mathrm{J}, \mathrm{Wu} \mathrm{J}$ et al (2014) Circulation of reassortant influenza A (H7N9) viruses in poultry and humans, Guangdong Province, China, 2013. Emerg Infect Dis 20:2034-2040

6. Wang X, Fang S, Lu X et al (2014) Seroprevalence to avian influenza A (H7N9) virus among poultry workers and the general population in southern China: a longitudinal study. Clin Infect Dis 59:76-83

7. Chen Z, Li K, Luo L et al (2014) Detection of avian influenza A (H7N9) virus from live poultry markets in Guangzhou, China: a surveillance report. PLoS One 9:e107266

8. Tan KX, Jacob SA, Chan KG, Lee LH (2015) An overview of the characteristics of the novel avian influenza A H7N9 virus in humans. Microbiology 6:1-11

9. Nerome K, Sugita S, Kuroda K et al (2015) The large-scale production of an artificial influenza virus-like particle vaccine in silkworm pupae. Vaccine 33:117-125

10. Kim JH, Jacob J (2009) DNA vaccines against influenza viruses. Curr Top Microbiol Immunol 333:197-201

11. Winquist AG, Fukuda K, Bridges CB, Cox NJ (1999) Neuraminidase inhibitors for treatment of influenza A and B infections. MMWR Recomm Rep 48:1-9

12. Wanaratana S, Tantilertcharoen R, Sasipreeyajan J, Pakpinyo S (2010) The inactivation of avian influenza virus subtype H5N1 isolated from chickens in Thailand by chemical and physical treatments. Vet Microbiol 140:43-48

13. Shahid MA, Abubakar M, Hameed S, Hassan S (2009) Avian influenza virus (H5N1); effects of physico-chemical factors on its survival. Virol $\mathrm{J}$ 6:38

14. Sabracos L, Romanou S, Dontas I et al (2007) The in vitro effective antiviral action of povidone-iodine (PVP-I) may also have 
therapeutic potential by its intravenous administration diluted with Ringer's solution. Med Hypotheses 68:272-274

15. Hidari KIPJ, Tsujii E, Hiroi J et al (2004) In vitro and in vivo inhibitory effects of disodium cromoglycate on influenza virus infection. Biol Pharm Bull 27:825-830

16. Zhao L, Huo CH, Shen LR et al (2010) Chemical constituents of plants from the genus Melia. Chem Biodivers 7:839-859

17. Pifarré MP, Berra A, Coto CE, Alché LE (2002) Therapeutic action of meliacine, a plant-derived antiviral, on HSV-induced ocular disease in mice. Exp Eye Res 75:327-334

18. Alche LE, Ferek GA, Meo M, Coto CE, Maier MS (2003) An antiviral meliacarpin from leaves of Melia azedarach L. Z Naturforsch C 58:215-219

19. Bueno CA, Lombardi MG, Sales ME, Alché LE (2012) A natural antiviral and immunomodulatory compound with antiangiogenic properties. Microvasc Res 84:235-241
20. Sanna G, Madeddu S, Giliberti G et al (2015) Limonoids from Melia azedarach fruits as inhibitors of flaviviruses and Mycobacterium tuberculosis. PLoS One 10:e0141272

21. Bitencourt RG, Queiroga CL, Duarte GHB et al (2014) Sequential extraction of bioactive compounds from Melia azedarach $\mathrm{L}$. in fixed bed extractor using $\mathrm{CO}_{2}$, ethanol and water. J Supercrit Fluids 95:355-363

22. Brankston G, Gitterman L, Hirji Z, Lemieux C, Gardam M (2007) Transmission of influenza A in human beings. Lancet Infect Dis $7: 257-265$

23. Moser MR, Bender TR, Margolis HS et al (1979) An outbreak of influenza aboard a commercial airliner. Am J Epidemiol 110:1-6 